\title{
REVIEW
}

Open Access

\section{Oncological outcomes of laparoscopic versus open nephroureterectomy for the treatment of upper tract urothelial carcinoma: an updated meta-analysis}

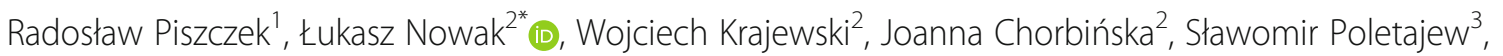
Marco Moschini ${ }^{4}$, Krzysztof Kaliszewski $^{5}$ and Romuald Zdrojowy ${ }^{2}$

\begin{abstract}
Background: During the past two decades, laparoscopic radical nephroureterectomy (LRNU) has been proposed as an alternative technique to open radical nephroureterectomy (ORNU) and has become increasingly accepted for the treatment of patients with upper tract urothelial carcinoma (UTUC). Nevertheless, the oncologic efficacy of LRNU remains controversial, especially for the treatment of locally advanced (T3/T4 and/or N+) UTUC. In this metaanalysis, we aimed to cumulatively compare the oncological outcomes of LRNU versus ORNU.

Materials and methods: The present meta-analysis was performed according to the Preferred Reporting Items for Systematic Reviews and Meta-Analyses (PRISMA) statement. A search was conducted of three electronic databases, namely, Medline, Embase, and Cochrane Library. Outcome measurements of cancer-specific survival (CSS), overall survival (OS), intravesical recurrence-free survival (IVRFS), and recurrence-free survival (RFS), including hazard ratios (HRs) and 95\% confidence intervals (Cls), were extracted and pooled.

Results: Eighteen articles published from 2007 to 2020 were included in the final quantitative analysis. One study was a randomized controlled trial $(\mathrm{RCT})$, and the remaining articles had a retrospective design. Among a total of 10, 730 participants in the selected papers, 5959 (55.5\%) and 4771 (44.5\%) underwent ORNU and LRNU, respectively. The results of pooled analyses revealed no significant differences in CSS (HR 0.84, 95\% Cl 0.60-1.19, $p=0.33$ ), OS (HR 0.84, 95\% Cl 0.62-1.13, $p=0.25$ ), IVRFS (HR 1.08, 95\% Cl 0.85-1.39, $p=0.52$ ), and RFS (HR 1.09, 95\% Cl 0.94-1.25, $p=0.26$ ) between LRNU and ORNU groups. Furthermore, the results of subgroup analyses for $\mathrm{pT} 3 / \mathrm{T} 4$ and pTany $\mathrm{N}+$ populations did not confirm any statistically significant differences between LRNU and ORNU in terms of any survival parameter.

Conclusions: Our present meta-analysis of current evidence suggests that LRNU and ORNU have comparable oncological outcomes in patients with UTUC, even in those with locally advanced disease. Further multicenter RCTs with large sample sizes and uniform data regarding specific surgical procedures, such as bladder cuff excision, are required to establish definitive conclusions.
\end{abstract}

Keywords: Upper tract urothelial carcinoma, Open nephroureterectomy, Laparoscopic nephroureterectomy

\footnotetext{
* Correspondence: Illukasz.nowak@gmail.com

${ }^{2}$ Department of Urology and Urological Oncology, Wroclaw Medical University, Borowska 213 Street, 50-556 Wroclaw, Poland

Full list of author information is available at the end of the article
}

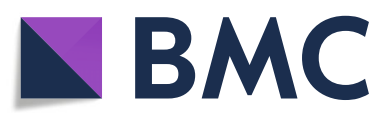

(c) The Author(s). 2021 Open Access This article is licensed under a Creative Commons Attribution 4.0 International License, which permits use, sharing, adaptation, distribution and reproduction in any medium or format, as long as you give appropriate credit to the original author(s) and the source, provide a link to the Creative Commons licence, and indicate if changes were made. The images or other third party material in this article are included in the article's Creative Commons licence, unless indicated otherwise in a credit line to the material. If material is not included in the article's Creative Commons licence and your intended use is not permitted by statutory regulation or exceeds the permitted use, you will need to obtain permission directly from the copyright holder. To view a copy of this licence, visit http://creativecommons.org/licenses/by/4.0/ The Creative Commons Public Domain Dedication waiver (http://creativecommons.org/publicdomain/zero/1.0/) applies to the data made available in this article, unless otherwise stated in a credit line to the data. 


\section{Introduction}

Upper tract urothelial carcinoma (UTUC) is an uncommon neoplasm accounting for approximately $5-10 \%$ of all urothelial cancers [1]. It refers to any malignancies that arise from the urothelial lining of the upper urinary tract, from the calyceal system up to the ureteral opening into the bladder [1]. Although overall incidence of UTUC has decreased, the incidence of metastatic UTUC has increased in the recent years [2].

According to the European Association of Urology (EAU) guidelines, open radical nephroureterectomy (ORNU) with bladder cuff excision is the standard treatment for high-risk UTUC [3]. However, during the past two decades, laparoscopic radical nephroureterectomy (LRNU) has been proposed as an alternative technique to the open approach and has become increasingly accepted for UTUC treatment [4]. Nevertheless, a sole randomized controlled trial (RCT) raised the hypothesis that patients with UTUC might have worse oncological outcomes if treated with a laparoscopic approach, particularly for locally advanced cases [5]. Since the publication of the last systematic review and meta-analysis [6], several studies that compared the oncological outcomes between LRNU and ORNU have been published, including large multicenter trials with matched cohorts. Therefore, we sought to perform an updated quantitative synthesis of data from the available literature. In this meta-analysis, we aimed to compare the oncological outcomes of LRNU versus ORNU in patients with UTUC.

\section{Material and methods}

\section{Search strategy}

This meta-analysis was performed according to the Preferred Reporting Items for Systematic Reviews and Meta-Analyses (PRISMA) statement and the Cochrane Handbook for Systematic Reviews of Interventions [7, 8]. Study protocol was registered with PROSPERO (CRD42021239989). Two review authors (RP and LN) independently conducted a systematic search of three electronic databases, namely, Medline, Embase, and Cochrane Library. The most recent search was performed on 18 March 2021. Screening of the literature was conducted using the following terms/keywords: ("upper tract urothelial carcinoma" OR "upper urinary tract carcinoma" OR "upper tract" OR "UTUC" OR "UUTC") AND ("laparoscopic" OR "laparoscop"” OR "LNU" OR "LRNU") AND ("open" OR "conventional" OR "ONU" OR "ORNU" OR "surgery"). No specific time or language restrictions were applied. A cross-referenced search was also performed from articles selected for fulltext review. Additional articles were screened from ahead of print articles in various urological journals.

\section{Selection criteria}

We evaluated studies for inclusion and exclusion based on a predefined PICOS approach where the population $(\mathrm{P})$, intervention (I), comparator group (C), outcome $(\mathrm{O})$, and study design $(\mathrm{S})$ were considered. The inclusion criteria were as follows: (P) studies that involved patients with UTUC; (I) patients who underwent LRNU; (C) compared with those who underwent ORNU; (O) cancer-specific survival (CSS), overall survival (OS), intravesical recurrence-free survival (IVRFS), and recurrence-free survival (RFS); and (S) prospective and retrospective trials. Prospective RCTs were considered eligible without any additional limitations, whereas retrospective papers had to provide data from multivariable analyses adjusted for at least one major confounder. Only studies reporting median follow up of a minimum of 12 months were included. To avoid small sample bias, only studies with a minimum of 50 patients were considered eligible for pooling survival estimates. Case reports, case series, conference abstracts, reviews, and letter to editors were excluded after the initial screening.

\section{Data extraction}

After removal of duplicates, two review authors (RP and $\mathrm{LN}$ ) independently screened titles and abstracts of the retrieved records using a standardized item form. All potentially eligible studies were evaluated as full text if available. In the case of multiple reports of the same cohort, the most complete data aggregated with the longest follow-up duration was selected. In the case of any discrepancy over inclusion of a particular study, a final decision was established after reaching a consensus with the other authors.

The following data were initially extracted: first author, year of publication, study region, study design, number of patients who underwent ORNU and LRNU, and median follow-up. Furthermore, the following clinicopathological data were retrieved: LRNU approach, method of bladder cuff excision, pathological tumor stage and grade, rates of patients with pathologically confirmed lymph nodes (LN) metastases, rates of patients with concomitant carcinoma in situ (CIS), rates of patients with lymphovascular invasion (LVI), rates of patients with positive surgical margins (PSM), and proportion of patients receiving neoadjuvant (NAC) and adjuvant chemotherapy (AC). Subsequently, the outcome measurements of CSS, OS, IVRFS, and RFS (including hazard ratios [HRs] and 95\% confidence intervals [95\% CIs]) were extracted. Missing information or clarifications were sought by contacting the primary authors; however, no additional data were received.

\section{Quality and risk of bias assessment}

The quality of the selected studies was assessed independently by two review authors (WK and RP). The 
evaluation of the methodological quality of the non-RCT and RCT was performed according to the NewcastleOttawa Scale (NOS) [9] and Jadad Scale (JS) [10], respectively.

The risk of bias (RoB) was determined using the pragmatic approach for the evaluation of nonrandomized studies by examining the adjustments for confounders according to the Cochrane Handbook for Systematic Reviews of Interventions [8]. The articles were therefore reviewed based on the adjustment for the effects of the following confounders: age, pathological tumor stage, pathological tumor grade, concomitant CIS, presence of LN metastases, presence of LVI, AC administration, and PSM. The RoB of each study was assessed independently by two authors (RP and WK), and all disagreements were resolved by consultation with the other authors.

Finally, we assessed the potential publication bias. Because visual interpretation of the funnel plot asymmetry is inherently subjective and should be interpreted carefully due to several possible explanations, publication bias assessment was mainly based on the Egger's and Begg's asymmetry tests results.

\section{Statistical analysis}

The statistical analysis was conducted using Review Manager 5.3 (The Nordic Cochrane Center, The Cochrane Collaboration, Copenhagen, Denmark) and Statistica 13.0 (TIBCO). From retrospective studies, we collected only reported multivariable HRs and 95\% CIs without performing any effect summary estimation methods. The statistical significance of the pooled HRs was evaluated by the $Z$ test. Statistical pooling of effect measures was based on the level of heterogeneity among studies. Significant heterogeneity was indicated by either ratio of $>50 \%$ in $I^{2}$ statistics or $p$ value of $<0.10$ in Cochrane's $Q$ test, which led to the use of the random-effect model. When no significant heterogeneity was observed, fixed-effect models were used for calculations. Additionally, meta-regression and subgroup analyses were conducted in order to relate specific study-level variables to the statistical heterogeneity between the results of the studies. For all tests (other than Cochrane's $Q$ test), $p<0.05$ was considered a statistically significant difference.

\section{Results}

Study population and risk of bias assessment

The flow diagram of study selection with subsequent exclusions is presented in Fig. 1. Our search strategy

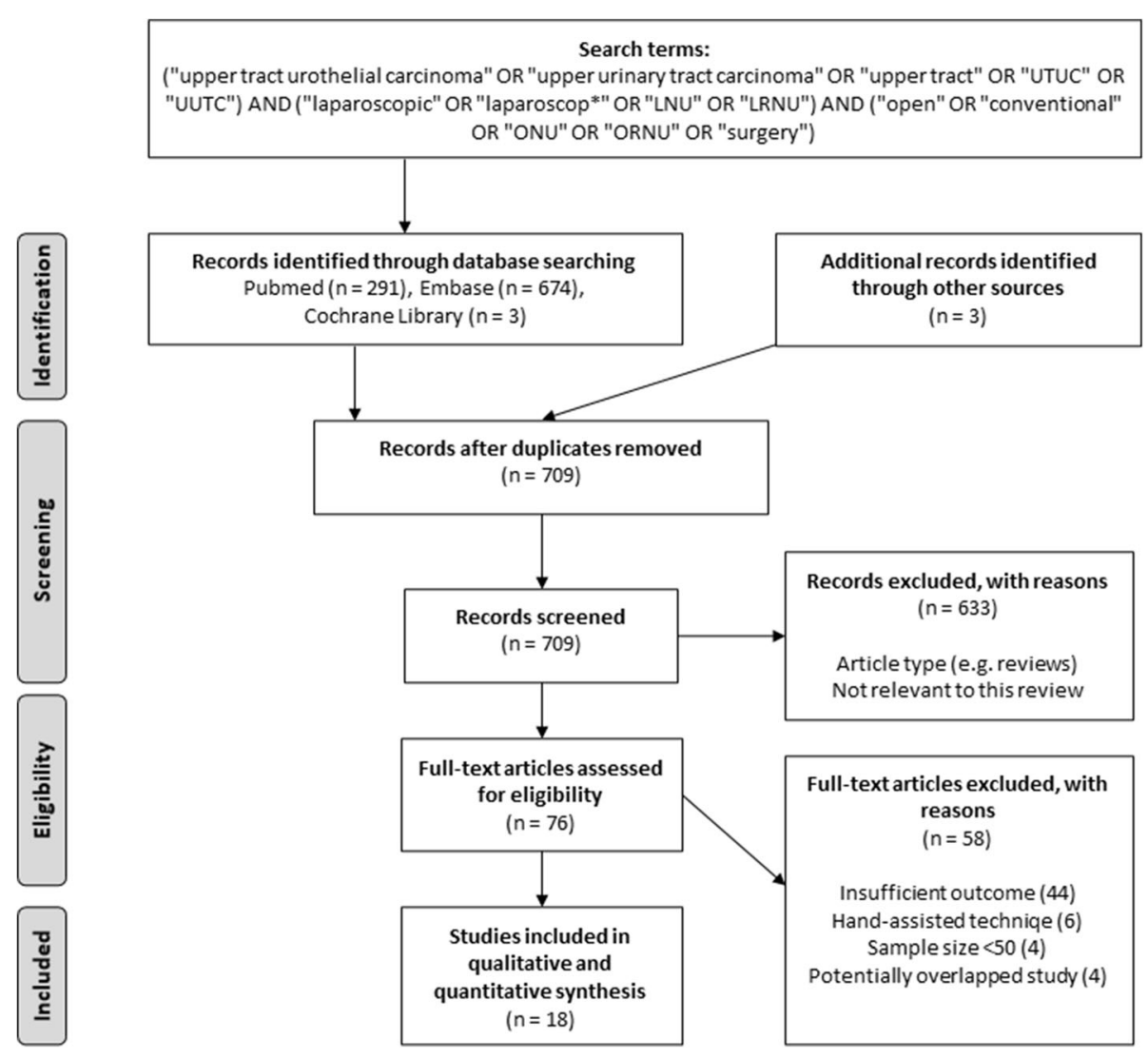

Fig. 1 Flow diagram of study selection 
initially identified 971 articles (968 from online databases and 3 from additional sources). Following deduplication $(n=709)$ and screening of the titles and abstracts, 633 studies were excluded because of inappropriate type (reviews, editorials, case reports, letters), irrelevance to present topic, or reporting robotic technique as an only comparative arm. Subsequently, 76 fulltext articles were assessed for eligibility and 58 were ultimately excluded due to the following: insufficient outcome $(n=44)$, inclusion of hand-assisted laparoscopic technique as an only comparative arm $(n=6)$, small sample size $(n=4)$, and overlap with previously reported studies $(n=4)$. Thus, 18 articles published from 2007 to 2020 were included in the final metaanalysis [5, 11-27].

Table 1 summarizes the main characteristics of studies included in this meta-analysis. One study was an RCT [5], and the remaining articles had a retrospective design [11-27]. Among a total of 10,730 patients in the selected papers, 5959 (55.5\%) and 4771 (44.5\%) underwent ORNU and LRNU, respectively. The reported median follow-up (for whole or individual LRNU/ORNU cohorts) was longer than 2 years in the majority of the selected papers. Assessment of quality scores by the NOS showed that the scores of included retrospective studies ranged from 6 to 8, which were considered appropriate for this meta-analysis. Jadad Scale score for single included RCT was 4 (representing good methodological quality).

The detailed data regarding surgical techniques and clinicopathological characteristics of patients in selected articles are presented in Table 2. LRNU was performed using a transperitoneal and retroperitoneal route in six $[5,11,18,19,22,27]$ and three $[17,21,26]$ studies, respectively. Transperitoneal or retroperitoneal access was reported in three publications $[15,20,25]$, and the remaining six articles did not report the route that was used [12-14, 16, 23, 24]. The approach for bladder cuff excision in the LRNU groups was not specified or was heterogeneous in 11 papers [11-17, 20, 22-24, 27]. The distal ureter was managed uniformly via an open extravesical and laparoscopic extravesical approach in six $[17-19,21,25,26]$ and one [5] studies, respectively. In the vast majority of studies, regional LN dissection was performed selectively in cases in which LN involvement was suspected on preoperative imaging or was identified during surgery. In two papers, LN dissection was not performed in any case $[5,21]$. Most studies did not report significant differences in pathological stage, grade, rates of concomitant CIS, LVI, and PSM, between the ORNU and LRNU groups. Eight studies [5, 12, 15, 17$19,25,26]$, reported similar rates of LN metastases between the ORNU and LRNU groups, and in eight studies $[11,13,14,16,22-24,27]$, rates of LN metastases were significantly higher in the ORNU group. Data regarding use of NAC were presented only in two selected papers $[17,23]$, whereas in other articles, patients receiving NAC were initially excluded or no data were available. Detailed data regarding AC administration were provided in 12 of 18 articles [14, 16-19, 21, 23-27].

All studies, with the exception of the RCT, carried a high RoB, which was primarily related to their retrospective design. Assessment of RoB and confounding for each individual study was presented in Fig. 2. Overall $\mathrm{RoB}$ and confounding was additionally provided in Supplementary Figure 1. In 8 of 17 retrospective studies, multivariate analyses were adjusted for the effect of at least five confounders, with age, pathological stage, and grade being the most common $[11,13,14,18,19,23,24$, 27]. Matching techniques (propensity-score matching or inverse probability weighting) were implemented in four of them $[17,19,24,25]$.

\section{Meta-analysis results}

For each outcome of interest (CSS, OS, IVRFS, RFS), we performed main analyses comprising data from main cohorts of all available publications. Subsequently, we conducted subgroup analyses of pT3/T4 and pTany $\mathrm{N}+$ populations. Surgical access (transperitoneal or retroperitoneal) and study design (retrospective or RCT) were used as stratification variables in additional subgroup analyses.

CSS data were reported in 11 included articles [5, 11, 13, 14, 17-19, 22, 24, 25, 27]. Significant heterogeneity was observed among the studies $\left(I^{2}=73 \% ; p<0.001\right)$; therefore, a random-effects model was used to analyze the outcome. A forest plot of $\mathrm{HR}$ and $95 \% \mathrm{CI}$ for CSS is presented in Fig. 3a. The results of pooled analysis revealed no significant difference in CSS between LRNU and ORNU (HR 0.84, 95\% CI 0.60-1.19, $p=0.33$ ). The results of asymmetry tests did not show any evidence of publication bias (Supplementary Table 1; funnel plot was shown in Supplementary Figure 2A).

OS data were reported in eight included articles [12, 14, 17-19, 22-24]. Significant heterogeneity was observed among the studies $\left(I^{2}=84 \% ; p<0.001\right)$; therefore, a random-effects model was used to analyze the outcome. A forest plot of HR and $95 \%$ CI for OS is presented in Fig. 3b. The results of pooled analysis revealed no significant difference in OS between LRNU and ORNU (HR 0.84, 95\% CI 0.62-1.13, $p=0.25$ ). The results of asymmetry tests did not show any evidence of publication bias (Supplementary Table 1; funnel plot was shown in Supplementary Figure 2B).

IVRFS data were reported in nine included articles [12, 15-18, 20-22, 25]. Significant heterogeneity was observed among the studies $\left(I^{2}=63 \% ; p=0.005\right)$; therefore, a random-effects model was used to analyze the 
Table 1 Baseline characteristics of included studies

\begin{tabular}{|c|c|c|c|c|c|c|c|}
\hline Study (year) & Country & Design & Duration & $\begin{array}{l}\text { Number of patients } \\
\text { (ORNU/LRNU) }\end{array}$ & $\begin{array}{l}\text { Follow up, median } \\
\text { (months) (ORNU/LRNU) }\end{array}$ & $\begin{array}{l}\text { Extracted } \\
\text { outcomes }\end{array}$ & $\mathrm{NOS}^{\mathrm{a}} / \mathrm{JS}^{\mathrm{b}}$ \\
\hline Ariane et al. (2012) [11] & France & R, multi-institutional & $1995-2010$ & $459 / 150$ & Whole cohort: 27 & CSS, RFS & $6^{a}$ \\
\hline Azawi et al. (2020) [12] & Denmark & $\begin{array}{l}\mathrm{R} \text {, population-based } \\
\text { registry }\end{array}$ & 2004-2017 & $321 / 1063$ & Whole cohort: 54 & OS, IVRFS & $6^{a}$ \\
\hline Capitanio et al. (2009) [13] & International & R, multi-institutional & 1987-2007 & $979 / 270$ & Whole cohort: 49 & CSS, RFS & $8^{\mathrm{a}}$ \\
\hline Fairey et al. (2013) [14] & Canada & R, multi-institutional & 1994-2009 & $403 / 446$ & Whole cohort: 26.4 & CSS, OS, RFS & $7^{\mathrm{a}}$ \\
\hline Favaretto et al. (2010) [15] & $\begin{array}{l}\text { United } \\
\text { States }\end{array}$ & $\mathrm{R}$, single-center & $2002-2008$ & $109 / 53$ & Whole cohort: 23 & IVRFS, RFS & $6^{\mathrm{a}}$ \\
\hline Fradet et al. (2014) [16] & Canada & R, multi-institutional & 1990-2010 & $267 / 345$ & Whole cohort: 40.4 & IVRFS & $7^{\mathrm{a}}$ \\
\hline Kido et al. (2018) [17] & Japan & R, multi-institutional & 1995-2017 & $351 / 75^{*}$ & $41 / 35$ & CSS, OS, IVRFS, RFS & $7^{\mathrm{a}}$ \\
\hline Kim HS et al. (2016) [18] & Korea & $\mathrm{R}$, single-center & 1992-2012 & $271 / 100$ & $57.6 / 38.8$ & CSS, OS & $8^{\mathrm{a}}$ \\
\hline Kim SH et al. (2019) [19] & Korea & R, multi-institutional & $2000-2012$ & $638 / 638^{* *}$ & $37.8 / 44.3$ & CSS, OS, IVRFS & $8^{\mathrm{a}}$ \\
\hline Kitamura et al. (2014) [20] & Japan & R, multi-institutional & $1995-2010$ & $34 / 65$ & Whole cohort: 60 & IVRFS & $6^{\mathrm{a}}$ \\
\hline Koda et al. (2007) [21] & Japan & $\mathrm{R}$, single-center & $1995-2005$ & $27 / 79$ & Mean: 46.2/16.4 & IVRFS & $8^{\mathrm{a}}$ \\
\hline Lee et al. (2019) [22] & Korea & $\mathrm{R}$, single-center & $2004-2017$ & $161 / 137$ & Mean: 41.7/38.1 & CSS, OS, IVRFS & $8^{\mathrm{a}}$ \\
\hline Lenis et al. (2018) [23] & $\begin{array}{l}\text { United } \\
\text { States }\end{array}$ & $\begin{array}{l}\mathrm{R} \text {, population-based } \\
\text { registry }\end{array}$ & $2000-2013$ & $338 / 380$ & NR & OS & $6^{a}$ \\
\hline Moschini et al. (2020) [24] & International & R, multi-institutional & $2006-2018$ & $757 / 757^{* *}$ & Whole cohort: 62 & CSS, OS, RFS & $8^{a}$ \\
\hline Shigeta et al. (2019) [25] & Japan & R, multi-institutional & 1990-2015 & $72 / 72^{* *}$ & Whole cohort: 65.4 & CSS, IVRFS & $7^{\mathrm{a}}$ \\
\hline Simone et al. (2009) [5] & Italy & $\mathrm{RCT}$, single-center & $2003-2006$ & $40 / 40$ & Whole cohort: 41 & CSS & $4^{\mathrm{b}}$ \\
\hline $\begin{array}{l}\text { Taweemonkongsap et al. } \\
\text { (2008) [26] }\end{array}$ & Thailand & $\mathrm{R}$, single-center & $2001-2007$ & $29 / 31$ & Mean: 27.9/26.4 & RFS & $7^{\mathrm{a}}$ \\
\hline Walton et al. (2011) [27] & International & R, multi-institutional & $1987-2008$ & $703 / 70$ & $36 / 17$ & CSS, RFS & $7^{\mathrm{a}}$ \\
\hline
\end{tabular}

*Inverse-probability weighted analysis

**Propensity-score matched analysis

Abbreviations: CSS, cancer-specific survival; IVRFS, intravesical recurrence-free survival; JS, Jadad Scale; LRNU, laparoscopic radical nephroureterectomy; NOS, Newcastle-Ottawa Scale; OS, overall survival; ORNU, open radical nephroureterectomy; R, retrospective; RCT, randomized controlled trial; RFS, recurrence-free survival

outcome. A forest plot of HR and 95\% CI for IVRFS is presented in Fig. 3c. The results of pooled analysis revealed that LRNU and ORNU were comparable in terms of IVRFS (HR 1.08, 95\% CI 0.85-1.39, $p=0.52$ ). The results of asymmetry tests showed potential evidence of publication bias (Supplementary Table; funnel plot was shown in Supplementary Figure 2C).

RFS data were reported in eight articles [11, 13-15, $17,24,26,27]$. Significant heterogeneity was not observed among the studies $\left(I^{2}=45 \% ; p=0.08\right)$; therefore, a fixed-effects model was used to analyze the outcome. A forest plot of HR and 95\% CI for RFS is presented in Fig. 3d. The results of pooled analysis revealed that LRNU and ORNU were comparable in in terms of RFS (HR 1.09, 95\% CI $0.94-1.25, p=0.26$ ). The results of asymmetry tests did not show any evidence of publication bias (Supplementary Table 1; funnel plot was shown in Supplementary Figure 2D).

The results of prespecified subgroup analyses for pT3/ T4 and pTany $\mathrm{N}+$ cohorts did not confirm any statistically significant differences between LRNU and ORNU in terms of any oncological outcome. Also, no association between particular surgical access and improved survival parameters was found. Detailed results of all subgroup analyses were presented in Table 3. The results of meta-regression models did not show any clear source of heterogeneity between the studies (Supplementary Table 2).

\section{Discussion}

In the present meta-analysis, we attempted to provide cumulatively summarized evidence regarding oncological outcomes of LRNU compared with those of ORNU. Our analyses demonstrated that laparoscopic and open approaches were equivalent in terms of oncological outcomes, including CSS, OS, IVRFS, and RFS.

The first studies comparing LRNU to ORNU in patients with UTUC were published in 1993. Subsequently, multiple authors have demonstrated that LRNU could be associated with equivalent or significantly better perioperative outcomes compared to ORNU, including parameters such as reduced blood loss, faster recovery, or shorter hospital stay $[28,29]$. However, debate continues within the urologic community about which approach is associated with superior oncological outcomes and definitive conclusions remain a matter of controversy.

Many investigators have proposed hypotheses regarding the possible inferiority of LRNU compared to ORNU 


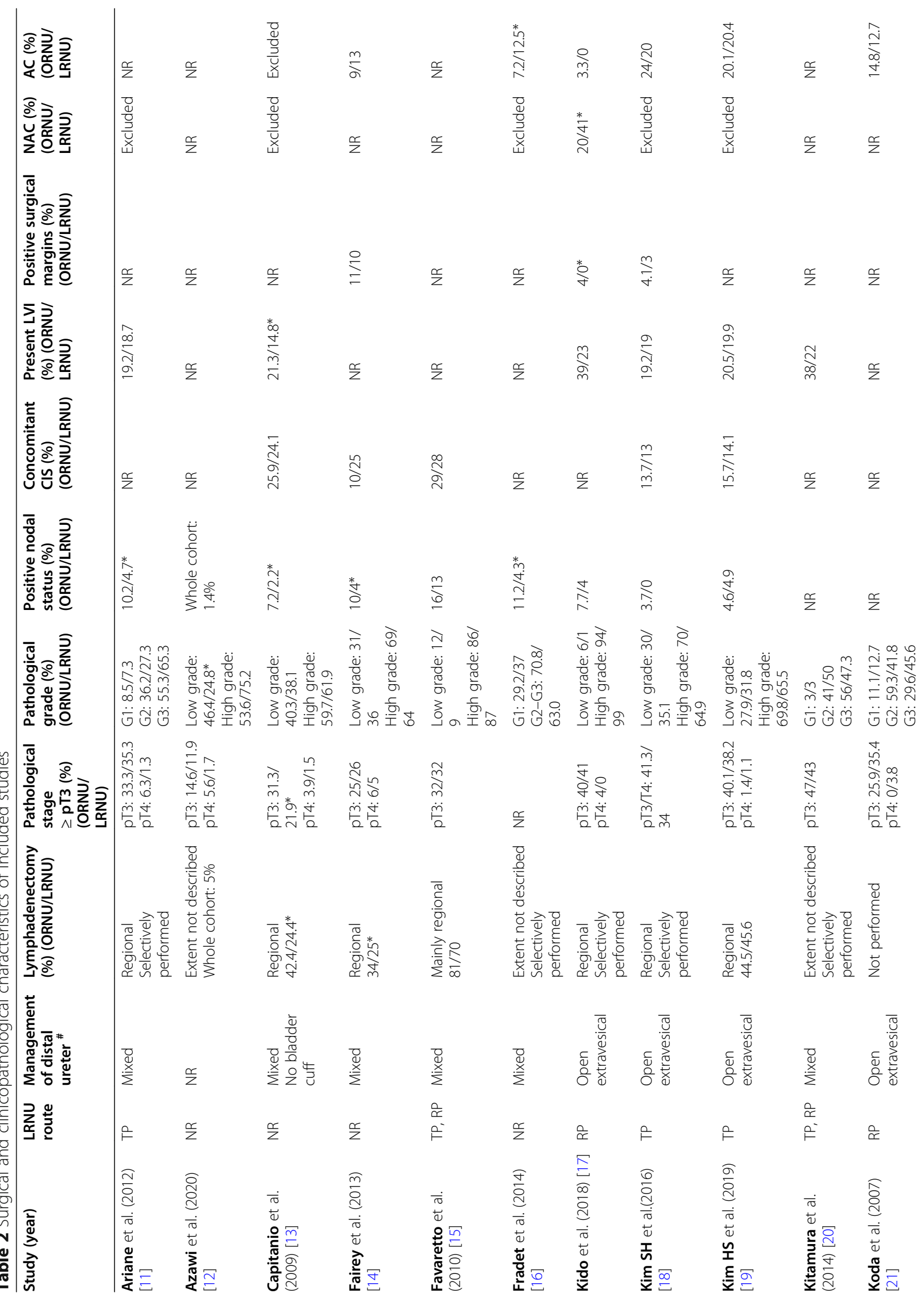




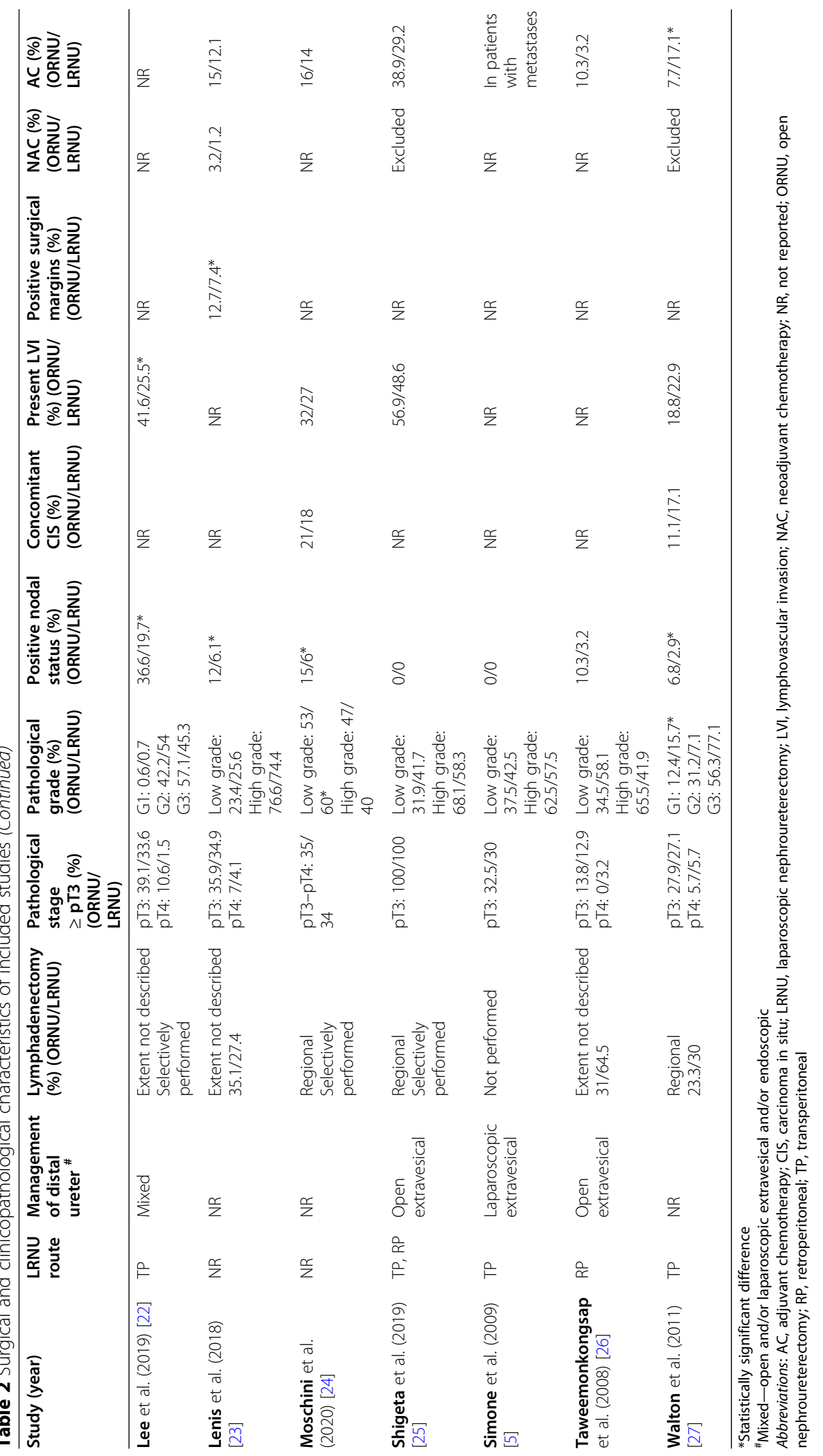




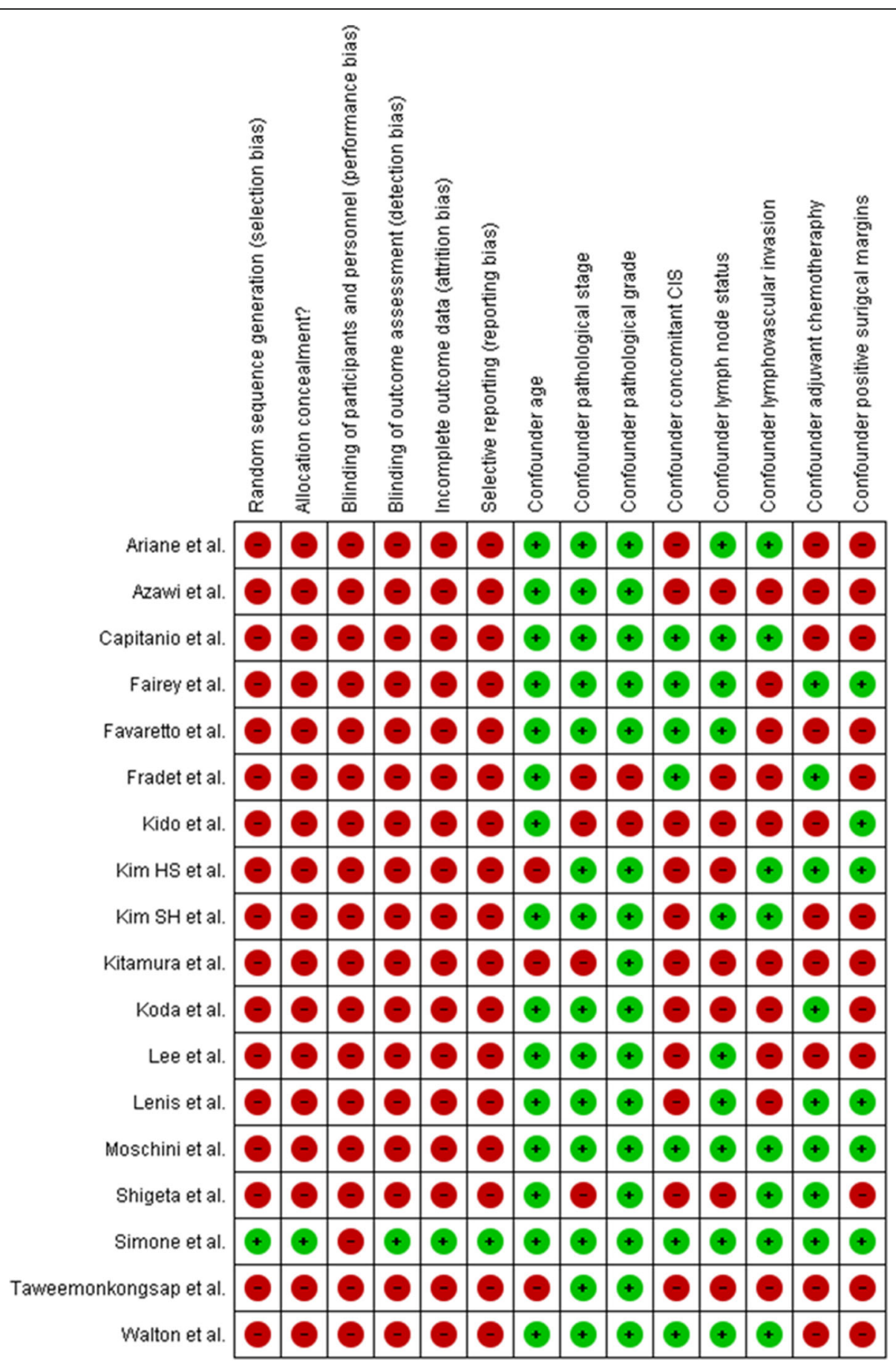

Fig. 2 The risk of bias and confounding assessment for all included studies. Green circles represent a low risk of bias and confounding; red circles represent a high risk of bias and confounding

in terms of oncological outcomes. First, concerns about the oncologic safety of LRNU have been attributed to the pneumoperitoneal environment. It has been postulated that manipulation within a tumor mass during increased intra-abdominal pressure might increase the risk of recurrence, because of gravitational effects leading to seeding and implanting cancer cells in the bladder or retroperitoneal space, especially in locally advanced tumors [30]. Nonetheless, the constant development of the LRNU technique, including use of closed systems and endobags, has clearly reduced this risk. In our prespecified subgroup analyses for locally advanced disease, 
A

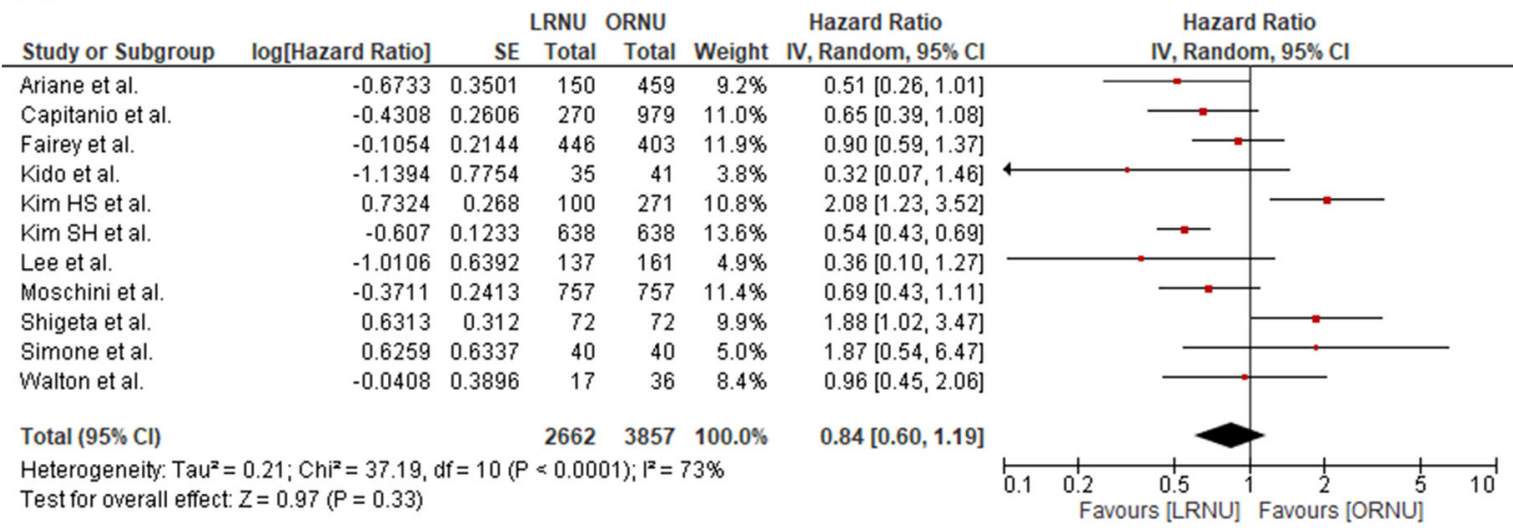

\section{B}

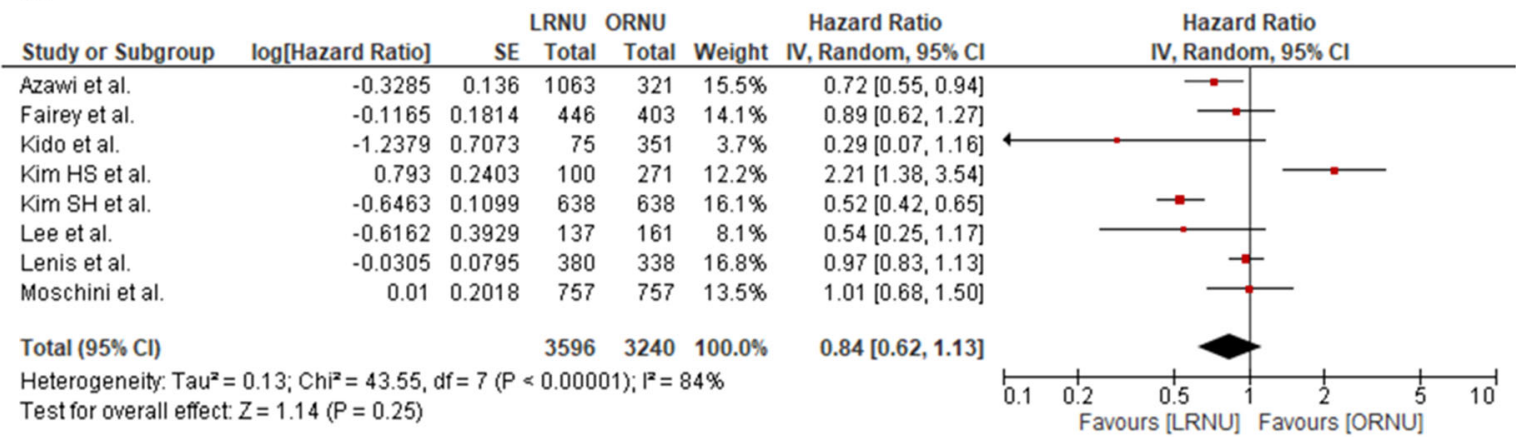

C

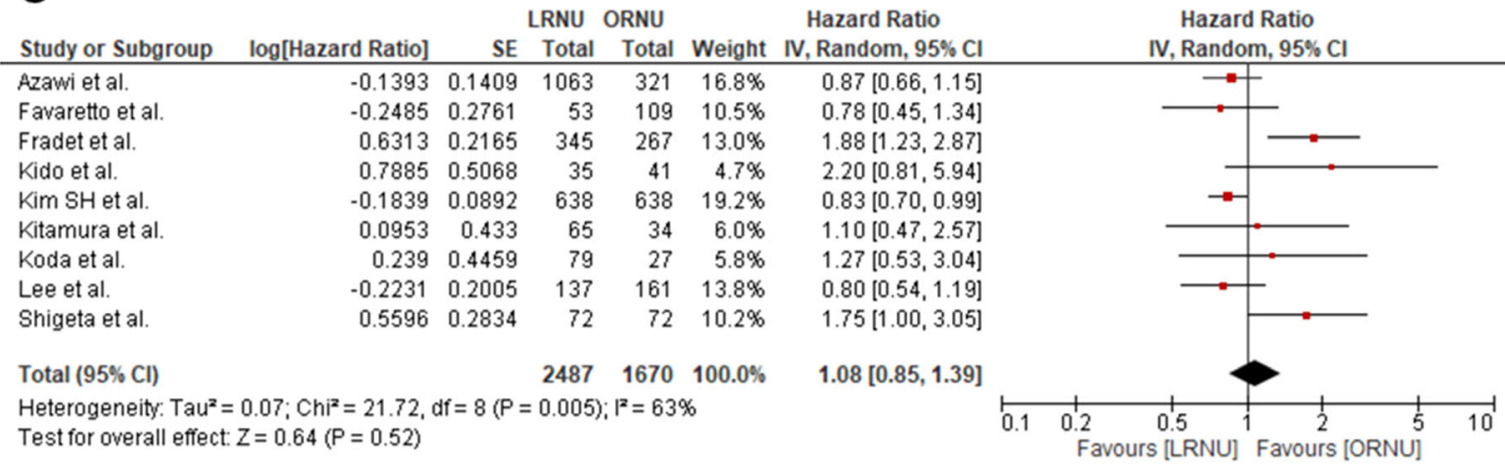

D

LRNU ORNU Hazard Ratio

Study or Subgroup $\quad \log [$ Hazard Ratio] SE Total Total Weight IV, Fixed, $95 \% \mathrm{Cl}$

$\begin{array}{lllllll}0.239 & 0.1872 & 150 & 459 & 15.1 \% & 1.27 & 0.881 .83]\end{array}$

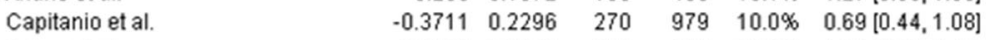

Fairey et al.

Favaretto et al.

$\begin{array}{llllll}0.2151 & 0.1204 & 446 & 403 & 36.4 \% & 1.24[0.98,1.57]\end{array}$

Kido et al.

Moschini et al.

$\begin{array}{llllll}-0.1278 & 0.2296 & 53 & 109 & 10.0 \% & 0.88\end{array}[0.56,1.38]$

Taweemonkongsap et al.

$\begin{array}{llllll}-0.6931 & 0.4937 & 75 & 351 & 2.2 \% & 0.50[0.19,1.32]\end{array}$

$\begin{array}{llllll}0.2852 & 0.1663 & 757 & 757 & 19.1 \% & 1.33[0.96,1.84]\end{array}$

Walton et al.

$\begin{array}{llllll}-0.4155 & 0.4196 & 31 & 29 & 3.0 \% & 0.66[0.29,1.50]\end{array}$

$\begin{array}{llllll}-0.2231 & 0.3537 & 70 & 703 & 4.2 \% & 0.80[0.40,1.60\end{array}$

Total $(95 \% \mathrm{Cl})$

$18523790 \quad 100.0 \% \quad 1.09[0.94,1.25]$

Heterogeneity. $\mathrm{Chi}^{2}=12.76, \mathrm{df}=7(P=0.08) ; \mathrm{I}^{2}=45 \%$

Test for overall effect: $Z=1.13(P=0.26)$

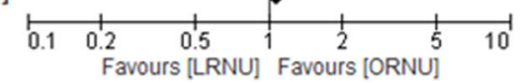

Fig. 3 Forest plot comparing survival parameters in patients undergoing LRNU vs. ORNU. a Cancer-specific survival. b Overall survival. c Intravesical recurrence-free survival. d Recurrence-free survival. Cl, confidence interval; IV, inverse variance; LRNU, laparoscopic radical nephroureterectomy; ORNU, open radical nephroureterectomy; SE, standard error 
Table 3 Subgroup analysis comparing oncological outcomes of LRNU vs. ORNU, stratified by pathological stage, surgical route, and study design

\begin{tabular}{|c|c|c|c|c|c|c|c|}
\hline Outcome & Variable & Subgroup & $\begin{array}{l}\text { No. of studies } \\
\text { [reference] }\end{array}$ & $\begin{array}{l}\text { No. of } \\
\text { patients } \\
\text { LRNU/ORNU }\end{array}$ & $\begin{array}{l}\text { HR }[95 \% \mathrm{Cl}] \\
\text { LRNU vs. } \\
\text { ORNU }\end{array}$ & $\begin{array}{l}P \\
\text { value }\end{array}$ & $\begin{array}{l}\text { Heterogeneity } \\
\text { (\%) }\end{array}$ \\
\hline \multirow[t]{6}{*}{ CSS } & \multirow[t]{2}{*}{ Pathological stage } & $\mathrm{pT} 3 / \mathrm{T} 4$ & $5[5,18,19,25,27]$ & $420 / 725$ & $1.51[0.95-2.38]$ & 0.08 & 74 \\
\hline & & pTany N+ & $2[19,27]$ & $33 / 77$ & $0.79[0.43-1.45]$ & 0.44 & 32 \\
\hline & \multirow{2}{*}{$\begin{array}{l}\text { Surgical access } \\
\text { (LRNU) }\end{array}$} & Transperitoneal & $6[5,11,18,19,22,27]$ & $1082 / 1605$ & $0.77[0.41-1.44]$ & 0.41 & 83 \\
\hline & & Retroperitoneal & $1[17]$ & $35 / 41$ & $0.32[0.07-1.46]$ & 0.14 & NA \\
\hline & \multirow[t]{2}{*}{ Study design" } & Retrospective & $\begin{array}{l}10[11,13,14,17-19,22,24,25, \\
27]\end{array}$ & $2622 / 3817$ & $0.81[0.57-1.15]$ & 0.24 & 74 \\
\hline & & $\begin{array}{l}\text { Randomized } \\
\text { controlled trial }\end{array}$ & $1[5]$ & $40 / 40$ & $1.87[0.54-6.47]$ & 0.26 & NA \\
\hline \multirow[t]{4}{*}{ os } & \multirow[t]{2}{*}{ Pathological stage } & $\mathrm{pT} 3 / \mathrm{T} 4$ & $2[19,23]$ & $285 / 377$ & $1.45[0.50-4.23]$ & 0.50 & 91 \\
\hline & & pTany N+ & $2[18,19]$ & $115 / 145$ & $0.92[0.53-1.59]$ & 0.76 & 58 \\
\hline & \multirow{2}{*}{$\begin{array}{l}\text { Surgical access } \\
\text { (LRNU) }\end{array}$} & Transperitoneal & $3[18,19,22]$ & $875 / 1070$ & $0.86[0.32-2.35]$ & 0.77 & 93 \\
\hline & & Retroperitoneal & $1[17]$ & $75 / 351$ & $0.29[0.07-1.16]$ & 0.08 & NA \\
\hline \multirow[t]{4}{*}{ IVRFS } & \multirow[t]{2}{*}{ Pathological stage } & $\mathrm{pT} 3 / \mathrm{T} 4$ & $2[19,25]$ & $323 / 337$ & $1.14[0.53-2.46]$ & 0.74 & 85 \\
\hline & & pTany N+ & $1[19]$ & $31 / 29$ & $1.48[0.68-3.22]$ & 0.32 & NA \\
\hline & \multirow{2}{*}{$\begin{array}{l}\text { Surgical access } \\
\text { (LRNU) }\end{array}$} & Transperitoneal & $2[19,22]$ & 775/799 & $0.83[0.70-1.07]$ & 0.06 & 0 \\
\hline & & Retroperitoneal & $2[17,21]$ & $114 / 68$ & $1.61[0.84-3.11]$ & 0.15 & 0 \\
\hline \multirow[t]{4}{*}{ RFS } & \multirow[t]{2}{*}{ Pathological stage } & $\mathrm{pT} 3 / \mathrm{T} 4$ & $2[14,27]$ & $143 / 347$ & $1.00[0.66-1.51]$ & 0.98 & 0 \\
\hline & & pTany N+ & $2[14,27]$ & $20 / 90$ & $1.59[0.62-4.07]$ & 0.33 & 30 \\
\hline & \multirow{2}{*}{$\begin{array}{l}\text { Surgical access } \\
\text { (LRNU) }\end{array}$} & Transperitoneal & $2[11,27]$ & $220 / 1162$ & $1.15[0.83-1.59]$ & 0.40 & 25 \\
\hline & & Retroperitoneal & $2[17,26]$ & $106 / 380$ & $0.59[0.31-1.10]$ & 0.10 & 0 \\
\hline
\end{tabular}

\footnotetext{
"Subgroup analysis was possible only for CSS
}

Abbreviations: Cl, confidence interval; CSS, cancer-specific survival; HR, hazard ratio; IVRFS, intravesical recurrence-free survival; LRNU, laparoscopic radical nephroureterectomy; NA, not applicable; ORNU, open radical nephroureterectomy; OS, overall survival; RFS, recurrence-free survival

stratified for $\mathrm{pT} 3 / \mathrm{T} 4$ and pTany $\mathrm{N}+$ populations, we did not confirm any statistically significant differences between LRNU and ORNU in terms of any survival parameter. Also, no significant differences were found regarding particular surgical access (transperitoneal vs. retroperitoneal).

Second, management of bladder cuff might play a critical oncological role. Unfortunately, we could not reliably perform subgroup analyses based on different approaches, because most studies included in the present meta-analysis reported heterogeneous populations in terms of bladder cuff management. The oncologic importance of complete bladder cuff excision is underscored by the fact that the risk of tumor recurrence within this residual ureteric stump can be as high as $30-65 \%$ [31]. The assumption of worse survival outcomes in patients treated with LRNU and laparoscopic excision of the bladder cuff and distal ureter was based on the results of a sole RCT, which was also included in this meta-analysis. In this RCT, all patients underwent laparoscopic bladder cuff excision and LRNU was associated with significantly worse CSS and metastatic-free survival [5]. Recently, Shigeta et al. evaluated the oncological outcomes of pure LRNU (laparoscopic bladder cuff resection) compared with conventional LRNU (open bladder cuff resection) using a multi-institutional collaboration dataset. The 3-year IVRFS rate was significantly lower in the pure LRNU group compared to the conventional LRNU group $(41.8 \%$ vs. $66.6 \%, p=0.004)$. In multivariate analysis, pure LRNU was found to be an independent risk factor for worse IVRFS. Although no significant differences in 3-year RFS were found between the two methods, atypical recurrence sites (brain, sigmoid colon, vagina, peritoneum) were observed in the pure LRNU group [32]. The potential explanation for these findings might be challenging technical aspects of laparoscopic bladder cuff excision, such as closure of the bladder, which increases the risk of urine spillage in the surgical bed. The pure laparoscopic approach also risks leaving behind viable ureteral mucosa [31, 32]. However, further RCTs would be necessary to confirm the superiority of particular bladder cuff excision methods.

It has to be emphasized that administration of perioperative chemotherapy could potentially impact on the oncological outcomes of patients with UTUC treated with LRNU or ORNU. In a recent meta-analysis, Leow et al. found an OS and CSS benefit for NAC over radical nephroureterectomy (RNU) alone [33]. Furthermore, 
after pooling data from 29 studies, including results of the POUT trial (NCT01993979), the authors showed significant OS, CSS, and disease-free survival benefits in those who received AC compared with those who underwent RNU alone [33]. Although several papers included in our meta-analysis were adjusted for the AC confounder, only one provided data for the separated cohort of patients receiving $\mathrm{AC}$, reporting no differences between LRNU and ORNU groups in terms of CSS and RFS [27]. Moreover, it has to be emphasized that in the majority of selected articles, patients receiving NAC were initially excluded or such data were not reported. As the RNU alone fails to manage significant number of high-risk UTUCs, there is an urgent need to combine surgery with systemic cancer control strategies. It was demonstrated by Margulis et al. that administration of four NAC cycles of accelerated methotrexate, vinblastine, doxorubicin, and cisplatin allows to achieve $14 \%$ complete pathological response rate (ypT0N0) in patients with high grade UTUC. Further, final pathological stage ypT1 or less was reported in more than $60 \%$ of patients [34]. Despite small sample size, the results of this study support the NAC feasibility in patients with UTUC, who are initially qualified for nephroureterectomy. Notwithstanding, current evidences are still lacking and future prospective trials are necessary to make definitive conclusions.

Several systematic reviews and meta-analyses that assessed the oncological outcomes of LRNU versus ORNU have been published to date. Initially, $\mathrm{Ni}$ et al. showed significantly higher rates of 5-year CSS for patients who underwent LRNU compared to those who underwent ORNU (9\%, $p=0.03)$. Conversely, the overall recurrence rate and bladder recurrence rate were significantly lower, at $15 \%(p=0.01)$ and $17 \%(p=0.02)$, respectively. No statistically significant differences in other survival parameters (2-year CSS, 5-year RFS, 5-year OS, 2-year OS, and metastasis rates) were found between LRNU and ORNU. The interpretation of these data was limited because patients managed with a laparoscopic approach were more likely to have $\mathrm{Ta} / \mathrm{Tis}$ or $\mathrm{T} 1$ disease and less likely to have T3 or T4 lesions [35]. Subsequently, Zhang et al. in their meta-analysis showed no differences in the OS, IVRFS, and unspecified RFS between LRNU and ORNU. However, improvements in the extravesical RFS and CSS were observed in the LRNU group. The results of this study should be interpreted cautiously, because of multiple methodological flaws, such as mixing the time-to-event data (HR) with the odds ratio [36]. Furthermore, Peyronnet et al. in their systematic review published in 2018 comprehensively reviewed the available evidence and suggested that the oncological outcomes of LRNU may be poorer than those of ORNU in patients with locally advanced high- risk (pT3/pT4 high-grade) UTUC, which was not confirmed in our meta-analysis [37]. In the most recent meta-analysis conducted by Liu et al., no significant differences in the rates of both 2-year and 5-year RFS, CSS, and OS were observed; however, no detailed subgroup analyses were performed [6].

All of the aforementioned meta-analytic studies have implicated potential risk factors and selection biases resulting from inclusion of retrospective studies. Through inclusion of data from multivariable analyses only (mainly adjusted for the effects of major confounders), we could minimize bias and establish the highest level of comparability to date. Since the publication of the most recent meta-analysis [6], seven new articles including overall 5760 participants have been published [12, 17, 19, 22-25]. Although all novel publications had retrospective design, matching techniques (propensity score matching, inverse probability weighting) were implemented in majority of them (contrary to the previously published original articles), making their results more reliable and less biased by retrospective design. Thus, the quality of available data improved since the publication of the last meta-analysis. Also, the major novelty of the current study are the subgroup analyses on non-organ confined patient.

Despite several strengths, this study is not devoid of limitations. First, the strength of the conclusions that can be drawn from our meta-analysis is still limited by the fact that almost all included studies were retrospective, with their own unavoidable limitations. Second, long-term follow-up was not reported in several studies. Third, the adjustments for confounders in the Cox regression analyses were not uniform in the included trials, which might introduce additional bias. Fourth, additional data regarding surgical approach (e.g., distal ureter management, bladder cuff excision, extent of LN dissection) were not uniformly reported and the influence of such significant heterogeneity could not be fully excluded. Fifth, the selection of the surgical procedure in patients with UTUC depends primarily on clinical stage; however, our subgroup analyses stratified by tumor stage were performed according to pathological stage, which potentially limits the conclusions with respect to current daily practice. Sixth, the results of subgroup analyses should be interpreted carefully, as available data are still limited.

\section{Conclusions}

The present meta-analysis of the current evidences confirms that LRNU and ORNU have comparable oncological outcomes in patients with UTUC, even in those with locally advanced disease. Further multicenter RCTs with large sample sizes and uniform data regarding specific surgical procedures, such as bladder cuff excision, are required to establish definitive conclusions. 


\section{Abbreviations}

AC: Adjuvant chemotherapy; Cl: Confidence interval; CIS: Carcinoma in situ; CSS: Cancer-specific survival; HR: Hazard ratio; IVRFS: Intravesical recurrencefree survival; LN: Lymph nodes; LRNU: Laparoscopic radical nephroureterectomy; LVI: Lymphovascular invasion; NAC: Neoadjuvant chemotherapy; NOS: Newcastle-Ottawa Scale; OS: Overall survival; ORNU: Open radical nephroureterectomy; PSM: Positive surgical margins; R: Retrospective; RCT: Randomized controlled trial; RFS: Recurrence-free survival; RoB: Risk of bias; UTUC: Upper tract urothelial carcinoma

\section{Supplementary Information}

The online version contains supplementary material available at https://doi. org/10.1186/s12957-021-02236-z.

Additional file 1: Supplementary Figure 1. Overall risk of bias graph. Additional file 2: Supplementary Figure 2. Funnel plot for the evaluation of potential publication bias: (A) cancer-specific survival; (B) overall survival; (C) intravesical recurrence-free survival; (D) recurrence-free survival.

Additional file 3: Supplementary Table 1. Results of asymmetry tests for publication bias assessment.

Additional file 4: Supplementary Table 2. Meta-regression according to methodological covariates.

\section{Acknowledgements}

None

\section{Authors' contributions}

The authors listed below have made substantial contributions to the intellectual content of the paper in the various sections described below. a) Conception and design: RP, ŁN, and WK. b) Acquisition of data: RP, $七 N$, and JC. c) Analysis and interpretation of data: RP, $Ł N$, and WK. d) Drafting of the manuscript: All authors. e) Critical revision of the manuscript for important intellectual content: RZ, WK, MM, and KK. f) Statistical analysis: $Ł N$. g) Administrative, technical, or material support: RZ and WK. The authors read and approved the final manuscript.

\section{Funding}

None

\section{Availability of data and materials}

All data generated or analyzed during this study are included in this published article.

\section{Declarations}

Ethics approval and consent to participate

Not applicable

\section{Consent for publication}

Not applicable

\section{Competing interests}

None of the contributing authors has any conflicts of interest, including specific financial interests and relationships and affiliations relevant to the subject matter or materials discussed in the manuscript.

\section{Author details}

'Department of Urology and Oncologic Urology, Lower Silesian Specialist Hospital, Fieldorfa 2 Street, 50-556 Wroclaw, Poland. ${ }^{2}$ Department of Urology and Urological Oncology, Wroclaw Medical University, Borowska 213 Street, 50-556 Wroclaw, Poland. ${ }^{3}$ Centre of Postgraduate Medical Education, Marymonecka 99/813 Street, 01-813 Warsaw, Poland. ${ }^{4}$ Klinik für Urologie, Luzerner Kantonsspital, Spitalstrasse, 6004, 16 Lucerne, Switzerland. ${ }^{5}$ Department of General, Minimally Invasive and Endocrine Surgery, Wroclaw Medical University, Borowska 213 Street, 50-556 Wroclaw, Poland.
Received: 29 December 2020 Accepted: 7 April 2021

Published online: 21 April 2021

\section{References}

1. Siegel RL, Miller KD, Jemal A. Cancer statistics, 2019. CA Cancer J Clin. 2019; 69(1):7-34. https://doi.org/10.3322/caac.21551.

2. Collà RC, Nocera L, Stolzenbach LF, Wenzel M, Cucchiara V, Tian Z, et al. Incidence and survival rates of contemporary patients with invasive upper tract urothelial carcinoma. Eur Urol Oncol. 2020;\$2588-9311(20):30181-4. https://doi.org/10.1016/j.euo.2020.11.005.

3. Rouprêt M, Babjuk M, Burger M, Capoun O, Cohen D, Compérat EM, et al. European Association of Urology Guidelines on Upper Urinary Tract Urothelial Carcinoma: 2020 Update. Eur Urol. 2021;79(1):62-79. https://doi. org/10.1016/j.eururo.2020.05.042.

4. Leow JJ, Liu Z, Tan TW, Lee YM, Yeo EK, Chong YL. Optimal management of upper tract urothelial carcinoma: current perspectives. Onco Targets Ther. 2020;13:1-15. https://doi.org/10.2147/OTT.S225301.

5. Simone G, Papalia R, Guaglianone S, Ferriero M, Leonardo C, Forastiere E, et al. Laparoscopic versus open nephroureterectomy: perioperative and oncologic outcomes from a randomised prospective study. Eur Urol. 2009; 56(3):520-6. https://doi.org/10.1016/j.eururo.2009.06.013.

6. Liu F, Guo W, Zhou X, Ding Y, Ma Y, Hou Y, et al. Laparoscopic versus open nephroureterectomy for upper urinary tract urothelial carcinoma: a systematic review and meta-analysis. Medicine (Baltimore). 2018;97:e11954 https://doi.org/10.1097/MD.0000000000011954.

7. Liberati A, Altman DG, Tetzlaff J, Mulrow C, Gøtzsche PC, loannidis JP, et al. The PRISMA statement for reporting systematic reviews and meta-analyses of studies that evaluate health care interventions: explanation and elaboration. PLoS Med. 2009;6(7):e1000100. https://doi.org/10.1371/journal. pmed. 1000100.

8. Higgins JPT, Thomas J, Chandler J, Cumpston M, Li T, Page MJ, et al Cochrane Handbook for Systematic Reviews of Interventions version 6.1 (updated September 2020). Cochrane; 2020. Available from www.training. cochrane.org/handbook. (Accessed 15 Nov 2020)

9. Wells G, Shea B, O'Connell D, Peterson J, Welch V, Losos M, et al. The Newcastle-Ottawa Scale (NOS) for assessing the quality of nonrandomised studies in meta-analyses. http://www.ohri.ca/programs/clinical epidemiology/oxford.asp. (Accessed 15 Nov 2020)

10. Jadad AR, Moore RA, Carroll D, Jenkinson C, Reynolds DJ, Gavaghan DJ, et al. Assessing the quality of reports of randomized clinical trials: is blinding necessary? Control Clin Trials. 1996;17(1):1-12. https://doi.org/10.1016/01 97-2456(95)00134-4

11. Ariane MM, Colin P, Ouzzane A, Pignot G, Audouin M, Cornu JN, et al. Assessment of oncologic control obtained after open versus laparoscopic nephroureterectomy for upper urinary tract urothelial carcinomas (UUTUCs): results from a large French multicenter collaborative study. Ann Surg Oncol. 2012;19(1):301-8. https://doi.org/10.1245/s10434-011-1841-x.

12. Azawi NH, Næraa SH, Subhi $Y$, Vásquez JL, Norus T, Dahl C, et al. Oncological outcomes of radical nephroureterectomy for upper urinary tract urothelial neoplasia in Denmark. Scand J Urol. 2020;54(1):58-64. https://doi.org/10.1080/21681805.2019.1710562.

13. Capitanio U, Shariat SF, Isbarn H, Weizer A, Remzi M, Roscigno M, et al. Comparison of oncologic outcomes for open and laparoscopic nephroureterectomy: a multi-institutional analysis of 1249 cases. Eur Urol. 2009:56(1):1-9. https://doi.org/10.1016/j.eururo.2009.03.072.

14. Fairey AS, Kassouf W, Estey E, Tanguay S, Rendon R, Bell D, et al. Comparison of oncological outcomes for open and laparoscopic radical nephroureterectomy: results from the Canadian Upper Tract Collaboration. BJU Int. 2013:112(6):791-7. https://doi.org/10.1111/j.1464-410X.2012.11474.x.

15. Favaretto RL, Shariat SF, Chade DC, Godoy G, Kaag M, Cronin AM, et al. Comparison between laparoscopic and open radical nephroureterectomy in a contemporary group of patients: are recurrence and disease-specific survival associated with surgical technique? Eur Urol. 2010;58(5):645-51. https://doi.org/10.1016/j.eururo.2010.08.005.

16. Fradet $\mathrm{V}$, Mauermann J, Kassouf W, Rendon R, Jacobsen N, Fairey A, et al. Risk factors for bladder cancer recurrence after nephroureterectomy for upper tract urothelial tumors: results from the Canadian Upper Tract Collaboration. Urol Oncol. 2014;32(6):839-45. https://doi.org/10.1016/j. urolonc.2014.04.006

17. Kido K, Hatakeyama S, Fujita N, Yamamoto H, Tobisawa Y, Yoneyama T, et al. Oncologic outcomes for open and laparoscopic radical 
nephroureterectomy in patients with upper tract urothelial carcinoma. Int J Clin Oncol. 2018;23(4):726-33. https://doi.org/10.1007/s10147-018-1248-9.

18. Kim HS, Ku JH, Jeong CW, Kwak C, Kim HH. Laparoscopic radical nephroureterectomy is associated with worse survival outcomes than open radical nephroureterectomy in patients with locally advanced upper tract urothelial carcinoma. World J Urol. 2016;34(6):859-69. https://doi.org/10.1 007/s00345-015-1712-3.

19. Kim SH, Song MK, Kim JK, Hong B, Kang SH, Ku JH, et al. Laparoscopy versus open nephroureterectomy in prognostic outcome of patients with advanced upper tract urothelial cancer: a retrospective, multicenter, propensity-score matching analysis. Cancer Res Treat. 2019;51(3):963-72. https://doi.org/10.4143/crt.2018.465

20. Kitamura H, Maeda T, Tanaka T, Fukuta F, Kobayashi K, Nishiyama N, et al. Comparison of laparoscopic, hand-assisted, and open surgical nephroureterectomy. JSLS. 2014;18(2):288-93. https://doi.org/10.4293/1 $08680813 \times 13794522666842$.

21. Koda S, Mita K, Shigeta M, Usui T. Risk factors for intravesical recurrence following urothelial carcinoma of the upper urinary tract: no relationship to the mode of surgery. Jpn J Clin Oncol. 2007;37(4):296-301. https://doi.org/1 0.1093/jijco/hym016.

22. Lee H, Kim HJ, Lee SE, Hong SK, Byun SS. Comparison of oncological and perioperative outcomes of open, laparoscopic, and robotic nephroureterectomy approaches in patients with non-metastatic uppertract urothelial carcinoma. PLoS One. 2019;14(1):e0210401. https://doi.org/1 0.1371/journal.pone.0210401.

23. Lenis AT, Donin NM, Faiena I, Salmasi A, Johnson DC, Drakaki A, et al. Role of surgical approach on lymph node dissection yield and survival in patients with upper tract urothelial carcinoma. Urol Oncol. 2018;36(9):e1-9. e9. https://doi.org/10.1016/j.urolonc.2017.09.001.

24. Moschini M, Zamboni S, Afferi L, Pradere B, Abufaraj M, Soria F, et al. Comparing oncological outcomes of laparoscopic vs open radical nephroureterectomy for the treatment of upper tract urothelial carcinoma: a propensity score-matched analysis [published online ahead of print, 2020 Jun 24]. Arab J Urol. 19(1):31-6. https://doi.org/10.1080/2090598X.2020.1817720

25. Shigeta K, Kikuchi E, Abe T, Hagiwara M, Ogihara K, Anno T, et al. Long-term oncologic outcomes of laparoscopic versus open radical nephroureterectomy for patients with T3NOMO upper tract urothelial carcinoma: a multicenter cohort study with adjustment by propensity score matching. Ann Surg Oncol. 2019;26(11):3774-81. https://doi.org/10.1245/s1 0434-019-07623-1.

26. Taweemonkongsap T, Nualyong C, Amornvesukit T, Leewansangtong $S$, Srinualnad S, Chaiyaprasithi B, et al. Outcomes of surgical treatment for upper urinary tract transitional cell carcinoma: comparison of retroperitoneoscopic and open nephroureterectomy. World J Surg Oncol. 2008;6(1):3. https://doi.org/10.1186/1477-7819-6-3.

27. Walton TJ, Novara G, Matsumoto K, Kassouf W, Fritsche HM, Artibani W, et al. Oncological outcomes after laparoscopic and open radical nephroureterectomy: results from an international cohort. BJU Int. 2011; 108(3):406-12. https://doi.org/10.1111/j.1464-410X.2010.09826.x.

28. Sugihara T, Yasunaga $H$, Yu C, Horiguchi H, Nishimatsu H, Fushimi K, et al. Perioperative outcome comparisons between open and laparoscopic nephroureterectomy among a population-based cohort from 2010 to 2012. J Endourol. 2015;29(7):770-6. https://doi.org/10.1089/end.2014.0428.

29. Hanna N, Sun M, Trinh QD, Hansen J, Bianchi M, Montorsi F, et al. Propensity-score-matched comparison of perioperative outcomes between open and laparoscopic nephroureterectomy: a national series. Eur Urol. 2012;61(4):715-21. https://doi.org/10.1016/j.eururo.2011.12.026.

30. Rouprêt M, Smyth G, Irani J, Guy L, Davin JL, Saint F, et al. Oncological risk of laparoscopic surgery in urothelial carcinomas. World J Urol. 2009;27(1): 81-8. https://doi.org/10.1007/s00345-008-0349-x.

31. Braun AE, Srivastava A, Maffucci F, Kutikov A. Controversies in management of the bladder cuff at nephroureterectomy. Transl Androl Urol. 2020;9:186880. https://doi.org/10.21037/tau.2020.01.17.

32. Shigeta K, Matsumoto K, Takeda T, Hattori S, Kaneko G, Matsushima M, et al. Evaluating the oncological outcomes of pure laparoscopic radical nephroureterectomy performed for upper-tract urothelial carcinoma patients: a multicenter cohort study adjusted by propensity score matching. Ann Surg Oncol. 2021;28(1):465-73. https://doi.org/10.1245/s1 0434-020-09046-9.

33. Leow JJ, Chong YL, Chang SL, Valderrama BP, Powles T, Bellmunt J. Neoadjuvant and adjuvant chemotherapy for upper tract urothelial carcinoma: a 2020 systematic review and meta-analysis, and future perspectives on systemic therapy. Eur Urol. 2020;50302-2838(20):30532-7. https://doi.org/10.1016/j.eururo.2020.07.003.

34. Margulis V, Puligandla M, Trabulsi EJ, Plimack ER, Kessler ER, Matin SF, et al. Phase II trial of neoadjuvant systemic chemotherapy followed by extirpative surgery in patients with high grade upper tract urothelial carcinoma. J Urol. 2020;203(4):690-8. https://doi.org/10.1097/JU.0000000000000644.

35. Ni S, Tao W, Chen Q, Liu L, Jiang H, Hu H, et al. Laparoscopic versus open nephroureterectomy for the treatment of upper urinary tract urothelial carcinoma: a systematic review and cumulative analysis of comparative studies. Eur Urol. 2012;61(6):1142-53. https://doi.org/10.1016/j.eururo.2012.02.019.

36. Zhang S, Luo Y, Wang C, Fu SJ, Yang L. Long-term oncologic outcomes of laparoscopic nephroureterectomy versus open nephroureterectomy for upper tract urothelial carcinoma: a systematic review and meta-analysis. PeerJ. 2016;4:e2063. https://doi.org/10.7717/peeri.2063.

37. Peyronnet $B$, Seisen T, Dominguez-Escrig JL, Bruins HM, Yuan CY, Lam T, et al. Oncological outcomes of laparoscopic nephroureterectomy versus open radical nephroureterectomy for upper tract urothelial carcinoma: an European Association of Urology Guidelines Systematic Review. Eur Urol Focus. 2019;5(2):205-23. https://doi.org/10.1016/j.euf.2017.10.003.

\section{Publisher's Note}

Springer Nature remains neutral with regard to jurisdictional claims in published maps and institutional affiliations.
Ready to submit your research? Choose BMC and benefit from:

- fast, convenient online submission

- thorough peer review by experienced researchers in your field

- rapid publication on acceptance

- support for research data, including large and complex data types

- gold Open Access which fosters wider collaboration and increased citations

- maximum visibility for your research: over $100 \mathrm{M}$ website views per year

At BMC, research is always in progress.

Learn more biomedcentral.com/submissions 